\title{
A PCR blood test outperforms chromogranin A in carcinoid detection and is unaffected by proton pump inhibitors
}

\author{
Irvin M Modlin', Harry Aslanian², Lisa Bodei ${ }^{1,2}$, Ignat Drozdov and Mark Kidd ${ }^{1}$ \\ 1 Wren Laboratories, 35 NE Industrial Road, Branford, Connecticut, USA and \\ ${ }^{2}$ Yale University School of Medicine, 310 Cedar St, New Haven, Connecticut, USA
}

Correspondence should be addressed to I M Modlin

Email

imodlin@optonline.net

\begin{abstract}
A critical requirement in neuroendocrine tumor (NET) management is a blood biomarker test that is sensitive, specific and reproducible. We evaluated a PCR-based 51-transcript signature to detect tumors, compared it with chromogranin $\mathrm{A}(\mathrm{CgA})$ and examined the confounding effect of proton pump inhibitors (PPIs), which cause falsely elevated CgA levels. The multigene signature was evaluated in two groups. Group 1: 125 prospectively collected NETs: gastroenteropancreatic NETs ( $n=91$, including 42 pancreatic and 40 small intestinal), carcinoids of unknown primary $(n=18)$ and other sites $(n=16)$. Group 2: prospectively collected non-NET patients receiving PPIs ( $>1$ month; dyspepsia, $n=19$; GERD, $n=6$; and pancreatitis, $n=4)$ and 50 controls. All samples were analyzed by PCR (marker genes) and ELISA (DAKO-CgA). Sensitivity comparisons included $\chi^{2}$, non-parametric measurements, and receiver operating characteristic (ROC) curves. Group 1: 123 NETs were PCR-positive (98.4\%) compared with 50 (40\%) CgA-positive $\left(\chi^{2}=97.3, P<10^{-26}\right)$. Significant differences $(P<0.001)$ were noted between pancreas: PCR $95 \%$ vs CgA $29.2 \%\left(P<10^{-9}\right)$ and small intestine: 100 vs $58 \%\left(P<10^{-4}\right)$. The multigene test was elevated in all grades (G1-G3), in both local and disseminated disease, and was not normalized by somatostatin analog therapy. It was also elevated in $97 \%$ of $\mathrm{CgA}$ normal NETs. Group 2: PPI administration increased CgA in $83 \%$ and $\mathrm{CgA}$ was elevated in $26 \%$ of controls. PCR values were not elevated in either group. PCR performance metrics were as follows: sensitivity $98.4 \%$, specificity $100 \%$, positive predictive value $100 \%$, negative predictive value $97.8 \%$, and the ROC-derived area under the curve (AUC) was 0.997 . These were significantly better than CgA (all metrics $<60 \%$; AUC, 0.54; Z-statistic, 10.44, $P<0.0001$ ). A 51-panel multigene blood transcript analysis is significantly more sensitive than plasma CgA for NET detection and is unaffected by acid suppression therapy.
\end{abstract}

\author{
Key Words \\ - biomarker \\ carcinoid \\ - chromogranin A \\ - gastroenteropancreatic \\ - neuroendocrine \\ - multigene transcript \\ - NET \\ - PCR \\ - proton pump inhibitor
}

Endocrine Connections (2014) 3, 215-223

\section{Introduction}

The National Cancer Institute (NCI) Neuroendocrine Tumor (NET) Summit conference proceedings of 2008 identified that a critical unmet need in the management of NET disease was the absence of a sensitive and specific set of tumor biomarkers (1). An accurate tumor marker is a critical tool in tumor management, because it establishes an uncertain diagnosis, offers a basis for individual prognostication, signals response to therapy, and identifies

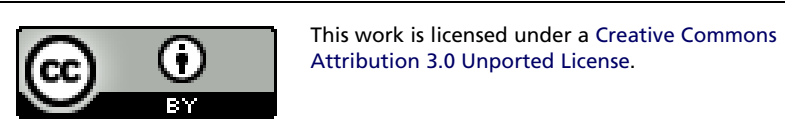


relapse. In classical terms, a high-quality tumor marker should represent a biologic attribute unique to the tumor cell or its local environment. Although this has proved manageable in a homogenous tumor population, the goal has been difficult to attain in gastroenteropancreatic NETs (GEP-NETs) as they comprise a heterogeneous group of cancers. Thus, tumor types range from histamine-secreting gastric 'carcinoids' to a mélange of pancreatic lesions (secreting glucagon, insulin, somatostatin, or vasoactive polypeptide - colloquially known as islet cell tumors), as well as small intestinal 'carcinoids' (secretin, serotonin, and a variety of tachykinins) and colorectal lesions (enteroglucagon, GLP1, and pancreatic polypeptide (PP)). The conundrum of identifying a global marker for NETs therefore has remained a substantial technical challenge.

A diverse variety of potential biomarkers has been proposed to be of utility in NET disease $(2,3,4,5)$. These include the constitutive neurosecretory protein chromogranin A (CgA) as well as individual secreted products, e.g. gastrin, serotonin, $\mathrm{PP}$, neurokinin $\mathrm{A}$, and VIP, or metabolic degradation products, e.g. urinary 5-HIAA. In general, these have proven to be relatively ineffective as biomarkers for a number of reasons. These include that they may only identify small subsets of lesions (specific, rare tumor types, e.g. VIPoma), the assays are not widely available (e.g. neurokinin A) or they are insensitive (e.g. PP in pancreatic NETs $\sim 50 \%$ sensitivity) (6), or there is a difficulty with the technique of collection (requires special diet and $24 \mathrm{~h}$ urine collection) (e.g. 5-HIAA). Furthermore, the overall performance metrics for these markers are low with $<50 \%$ sensitivity with $<30 \%$ specificity $(2,7,8)$.

In general, $\mathrm{CgA}$ has, in the last decade, been widely utilized as the NET default biomarker (9). Its utility has been reflected in its generally broad NET recognition profile (10). Although elevated levels of CgA are generally considered to be sensitive, $\sim 60-90 \%$ accurate (11), it is ineffective as a first-line diagnostic for NETs (12). This reflects that measurements are non-specific (10-35\% specificity) because CgA is elevated in other neoplasias, e.g. pancreatic and small-cell lung neoplasias and prostate carcinomas (13), and can be raised by a variety of cardiac and inflammatory diseases (14) as well as in renal failure (15). One of the commonest causes of spuriously elevated CgA levels is proton pump inhibitor (PPI) administration (10). A third of the USA population has been assessed to take acid-suppressive medications, e.g. PPIs $(16,17)$. Typically, more than $30 \%$ of persons over the age of 65 are estimated to use them $(18,19)$. The widespread use of PPIs is therefore a problematic confounder for a $\mathrm{CgA}$ biomarker assay.
Given the limited accuracy of the currently available biomarkers and the known limitations of single analyte measurements $(20,21)$, we developed a blood-based multianalyte NET-specific gene transcript analysis - the NETest. This is a robust, reproducible, PCR-based 51-marker peripheral blood signature (multigene test) with high sensitivity (85-98\%) and specificity (93-97\%) for the detection of gut NETs or 'carcinoids' $(22,23)$. The signature can identify all types of GEP-NETs, including small non-metastatic tumors, and significantly outperforms monoanalyte-based assays for detection $(22,24)$. In addition, the levels correlate with clinical status, e.g. stable or progressive disease (25). Based upon mathematical analyses of multianalyte methodology, this technique was determined to be superior to single-analyte assays in the detection of NETs (26).

The NETest conforms to a category of assays identified as Multianalyte Assays with Algorithmic Analyses (MAAAs), which include procedures that utilize multiple results derived from the assays of various types, including molecular pathology assays, e.g. breast cancer arrays (Mammaprint), fluorescent in situ hybridization assays, and non-nucleic acid-based assays (27). Algorithmic analyses, using the results of these assays as well as patient information (if available), are typically reported as a numeric score(s) or as a probability, often a risk probability (28), that can provide prognostic and predictive information, thereby aiding clinical decision-making (29). The strengths of MAAAs are the incorporation of multiple data sets as well as that these are typically undertaken by a single dedicated facility (30). Based on the need for an accurate test to assess NETs, we evaluated the specificity of the PCR-based test to detect tumors in comparison with CgA with particular reference to the confounding variable of PPI usage.

\section{Methods}

\section{Sample collection}

All samples were prospectively collected and analyzed according to a standard IRB protocol (Yale University: 6/17/2013) in accordance with the World Medical Association Declaration of Helsinki regarding the ethical conduct of research involving human subjects (22). All individuals from whom blood was obtained were present (6/2012$12 / 2013$ ) at the School of Medicine out-patient clinics following an informed consent. The blood samples $(5 \mathrm{ml})$ were collected in $9 \mathrm{mg} \mathrm{K}_{2}$ EDTA tubes (BD Vacutainer Venous Blood Collection Tubes, BD Diagnostics, Franklin, NJ, USA). The aliquots of whole blood were stored at $-80^{\circ} \mathrm{C}$ within $2 \mathrm{~h}$

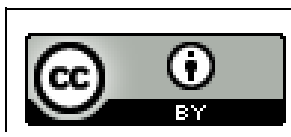

This work is licensed under a Creative Commons Attribution 3.0 Unported License. 
Table 1 Clinical characteristics of Group 1, NETs (includes GEP-NETs $(n=91)$, CUP $(n=18)$, and other sites $(n=16)$ ). Mean age 56.7 (range 25-82 years), gender: 40 males to 85 females, $n=125$.

\begin{tabular}{l} 
Tumor \\
distribution \\
\hline Gastric \\
Duodenum \\
Pancreas \\
Small intestine \\
Appendix \\
Colorectal \\
CUP \\
Lung \\
Ovary \\
Biliary tree \\
Totals
\end{tabular}

\begin{tabular}{r} 
No. \\
\hline 3 \\
1 \\
41 \\
40 \\
3 \\
3 \\
18 \\
4 \\
1 \\
$11^{\mathrm{c}}$ \\
125
\end{tabular}

\begin{tabular}{|c|c|c|}
\hline \multicolumn{3}{|c|}{ Grade } \\
\hline G1 & $\mathrm{G} 2$ & G3 \\
\hline 0 & 1 & 2 \\
\hline 1 & 0 & 0 \\
\hline 17 & 17 & 1 \\
\hline 36 & 4 & 0 \\
\hline 3 & 0 & 0 \\
\hline 2 & 1 & 0 \\
\hline 1 & 10 & 1 \\
\hline 3 & 0 & 1 \\
\hline 0 & 1 & 0 \\
\hline 1 & 0 & 10 \\
\hline $64(51 \%)$ & $34(27 \%)$ & $15(12 \%)$ \\
\hline
\end{tabular}

\begin{tabular}{|c|c|}
\hline \multicolumn{2}{|c|}{ Stage } \\
\hline Local & Distant \\
\hline 3 & 0 \\
\hline 1 & 0 \\
\hline 19 & 16 \\
\hline 5 & 40 \\
\hline 1 & 2 \\
\hline 2 & 1 \\
\hline 1 & 11 \\
\hline 2 & 2 \\
\hline 0 & 1 \\
\hline 1 & 11 \\
\hline $35(28 \%)$ & $84(67 \%)$ \\
\hline
\end{tabular}

\begin{tabular}{ccc}
\hline \multicolumn{2}{c}{ Treatment } \\
\cline { 1 - 3 } Untreated & & Current SSAs \\
\cline { 1 - 1 } \cline { 3 - 3 } 3 & & 0 \\
1 & & 0 \\
3 & & 0 \\
10 & & 25 \\
1 & & 0 \\
1 & & 1 \\
4 & & 5 \\
0 & & 1 \\
0 & & 0 \\
4 & & 0 \\
$27(22 \%)$ & $32(26 \%)$
\end{tabular}

\begin{tabular}{c}
$\begin{array}{c}\text { Current } \\
\text { PPIs }\end{array}$ \\
\hline 0 \\
0 \\
11 \\
0 \\
0 \\
0 \\
0 \\
0 \\
0 \\
0 \\
$11(9 \%)$
\end{tabular}

CUP, carcinoid of unknown primary.

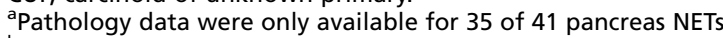

${ }^{b}$ Pathology data were only available for 12 of 18 CUPs.

'Ten were intrahepatic, one was extrahepatic.

of collection (samples immediately stored on ice at $4{ }^{\circ} \mathrm{C}$ after sampling) per standard molecular diagnostics protocols for PCR-based studies (31). A second aliquot $(2 \mathrm{ml})$ was spun $(600 \boldsymbol{g}, 10 \mathrm{~min})$ and the plasma collected for CgA ELISA using the DAKO Kit as described previously $(22,23,32)$.

\section{Study groups}

The clinical characteristics and details of the cases are included in Tables 1 and 2. These included Group 1: prospectively collected NETs $(n=125)$ and Group 2: prospectively collected non-NET patients taking PPIs who underwent endoscopic retrograde cholangiopancreatography (ERCP) or endoscopic ultrasound (EUS) for upper gastrointestinal (GI) symptoms $(n=29)$ at the Smilow Cancer Center, Yale New Haven Hospital. Group 1 included 91 GEP-NETs (gastric, $n=3$; duodenum, $n=1$; pancreas, $n=41$; small intestine, $n=40$; appendix, $n=3$; and colorectum, $n=3$ ), 18 with an unknown primary, and 16 non-GEP-NETs. Histopathologically, 51\% were G1, 27\% G2, and 12\% G3. Disease was localized in $28 \%$ and was distant in $67 \%$. No pathology and staging was available in $12(10 \%)$ patients. Twenty-two percent were treatment naïve, while $26 \%$ were currently being treated with somatostatin analogs, and $9 \%$ (11 patients, all Zollinger-Ellison syndrome (ZES)) were on concomitant PPIs. None of the patients were noted to have hypertension or abnormal kidney function (review of medication lists and clinical history). Group 2 included pancreatic cysts, $n=19$; pancreatitis, $n=4$; and gastroesophageal disease (GERD), $n=6$. Fifty additional controls were included to measure the performance metrics of the multigene scores and CgA.

\section{PCR multigene test}

A two-step manual technique protocol (RNA isolation with cDNA production and qPCR) was undertaken. The transcripts (mRNA) were isolated from $1 \mathrm{ml}$ blood samples collected in an EDTA-coated tube using the Mini Blood Kit (Qiagen). The RNA quantity was $50 \mu$, the quality was $>1.8$ $\left(\mathrm{A}_{260: 280}\right.$ ratio); the analysis of the RNA pattern on electrophoresis (Agilent Technologies, Santa Clara, CA, USA) RNA Integrity Number (RIN) >5.0 (33). The standard Qiagen isolation protocol (heme/gDNA contamination not detected) with no modifications was used. cDNA was produced from

Table 2 Clinical characteristics of Group 2.

\begin{tabular}{|c|c|}
\hline Characteristic & PPI users $^{\text {a }}(n=29)$ \\
\hline Mean age (range) (years) & $60(46-79)$ \\
\hline Gender (M:F) & 11:18 \\
\hline GI pathology (C:G:P) & $19: 6: 4$ \\
\hline
\end{tabular}

\begin{tabular}{c} 
Controls $(n=50)$ \\
\hline $47.1(28-75) *$ \\
$23: 27$ \\
-
\end{tabular}

\begin{tabular}{c} 
Combined $(n=79)$ \\
\hline $50.5(28-79)^{\dagger}$ \\
$34: 45^{\ddagger}$ \\
-
\end{tabular}

C, cyst; G, GERD; P, pancreatitis. * $P<0.005$ vs PPI (two-tailed Mann-Whitney $U$ test) ${ }^{\dagger} P<0.03$ vs NETs (two-tailed Mann-Whitney $U$ test). ${ }^{\ddagger} \chi{ }^{2}=2.5, P=$ NS vs NETs (Fisher's exact test, two-tailed).

${ }^{a}$ Treatment includes lansoprazole $(60 \mathrm{mg}, n=1)$, omeprazole ( $5 \mathrm{mg}, n=2 ; 20 \mathrm{mg}, n=4$; and $\left.40 \mathrm{mg}, n=6\right)$, pantoprazole (40 mg, $n=4$ and $\left.60 \mathrm{mg}, n=1\right)$, and rabeprazole $(20 \mathrm{mg}, n=1)$.
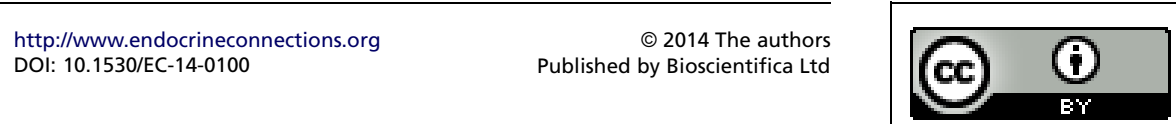
$50 \mu \mathrm{l}$ RNA using a high-capacity reverse transcriptase kit (Life Technologies: cDNA production 2000-2500 ng/ $\mu \mathrm{l}$ ) and stored at $-80{ }^{\circ} \mathrm{C}$. QPCR was carried out (384-well plate, HT-7900) with the cDNA (200 ng/ $\mu \mathrm{l})$ and $16 \mu \mathrm{l}$ of reagents/ well (Universal Master Mix II with UNG, Life Technologies, triplicate wells) $\left(50{ }^{\circ} \mathrm{C} 2 \mathrm{~min}, 95^{\circ} \mathrm{C} 10 \mathrm{~min}\right.$, then $95^{\circ} \mathrm{C} 15 \mathrm{~s}$, $60^{\circ} \mathrm{C}$, $60 \mathrm{~s}$ for 40 cycles) as described previously $(22,23)$. A NET score (0-8) is derived from the PCR data using MATLAB (R2011a, Mathworks, Natick, MA, USA) (25); a value $\geq 2$ is a positive tumor score $(22,23,25)$.

\section{Chromogranin A ELISA}

CgA was measured using the DAKO ELISA Kit (K0025, DAKO North America, Inc., Carpinteria, CA, USA) $(22,23,32)$. A cut-off of $19 \mathrm{U} / 1$ (DAKO) was used as the upper limit of normal. In preliminary studies, $75 \%$ of control samples $(n=36)$ exhibited levels <14 U/1 (22). An analysis identified that the recommended DAKO level of $19 \mathrm{U} / \mathrm{l}$ would result in a false positive of 3\% (22). This cut-off was used in the current study.

\section{Statistical analyses}

Sensitivity comparisons $\left(\chi^{2}\right.$, non-parametric measurements, and receiver operating characteristic (ROC) analysis) were made between the multigene test and plasma CgA (DAKOELISA) for the detection of NET. Both GraphPad Prism (LaJolla, CA, USA) and MedCalc (Ostend, Belgium) were utilized.

\section{Results}

\section{Group 1}

Prospectively collected NETs $(\boldsymbol{n}=125)$ - One hundred and twenty-three (98.4\%) had a PCR score $\geq 2$ (positive test). In contrast, 50 (40\%) exhibited an elevated CgA (Fig. 1A). The sensitivity of the PCR test for the detection of NETs was $98.4 \%$ (95\% CI: 94.3-99.8\%) vs 40\% (95\% CI: $31.2-49.4 \%)$ for $\mathrm{CgA}$. This was highly significant $\left(\chi^{2}=97.3\right.$, $\left.P<10^{-26}\right)$. A comparison between GEP-NETs $(n=91)$ and CUP $(n=18)$ or non-GEP-NETs $(n=16)$ identified no significant differences in PCR-based detection (97.8-100\%) between the different groups; CgA values for this group were (31-49.5\%, Fig. 1A) with a significantly lower prediction rate $(P<0.0005)$. An analysis of the individual GEP tumor sites $(n=91)$ identified that the PCR test was positive in $95-100 \%$ of samples (gastric, $100 \%$; duodenum, $100 \%$; pancreas, 95\%; small intestine, 100\%; appendix, 100\%; and
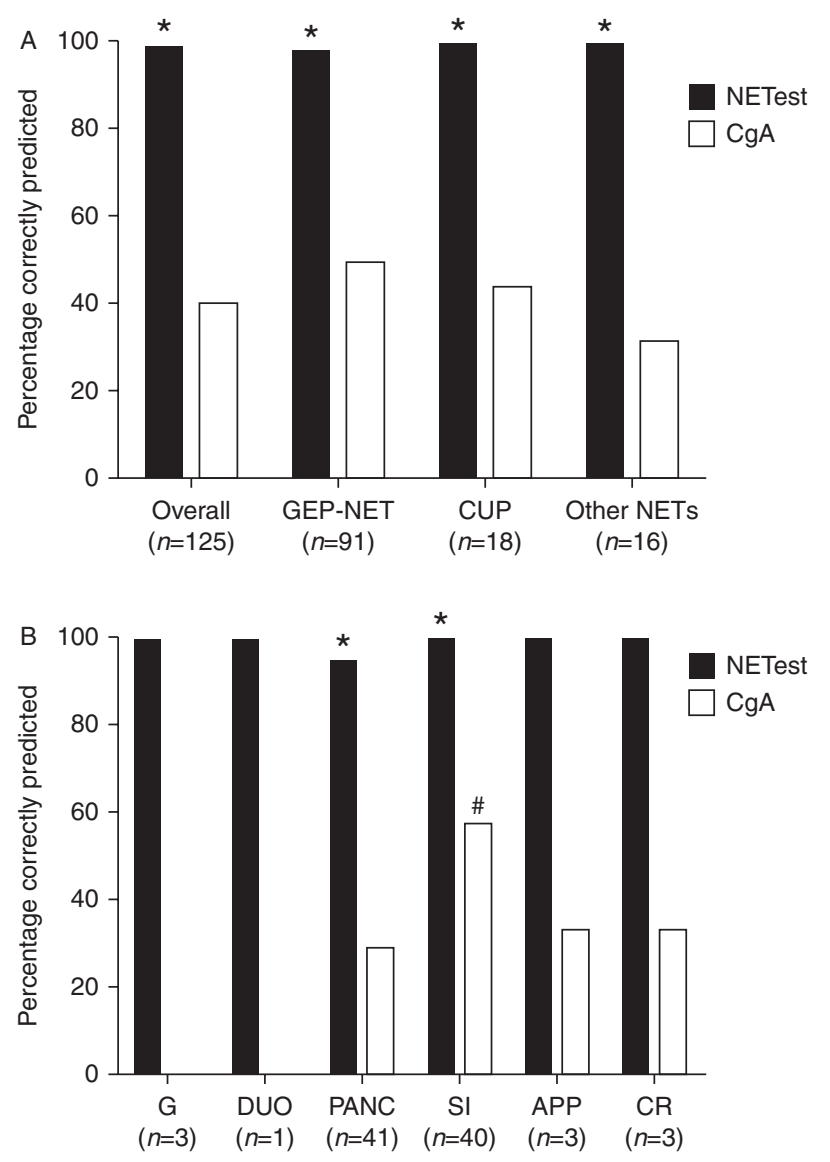

\section{Figure 1}

Accuracy of the multigene test compared with $\mathrm{CgA}$ for the detection of NETs (Group 1). (A) PCR analysis identified NETs in $>98 \%$ compared with 40-50\% with CgA. This was significantly better than CgA (*overall: $\chi^{2}=97.3, P<10^{-26} ;$ *GEP-NET: $\chi^{2}=52.3, P<10^{-14} ;{ }^{*}$ CUP: $\chi^{2}=11.2$, $P<0.0003$; and *other NETs: $\chi^{2}=13.8, P<0.00006$ ). (B) Assessment of primary site for GEP-NETs using PCR was $>95 \%$. CgA ranged from 0 to $56 \%$ correct cells. In the PANC and SI groups, the multigene test significantly out-performed CgA (*PANC: $\chi^{2}=35.1, P<10^{-9}$ and $*$ SI: $\chi^{2}=19.1, P<10^{-4}$ ). Significantly more $\mathrm{SI}$ cases were $\mathrm{CgA}$ positive than in the PANC group ( $\left.{ }^{\#} P<0.01\right)$. APP, appendix; $\mathrm{CgA}$, chromogranin $A ; C R$, colorectum; CUP, carcinoid of unknown primary; DUO, duodenum; G, gastric; GEP-NET, gastroenteropancreatic NET; PANC, pancreas; SI, small intestine.

colorectal, 100\%); CgA positivity ranged between 0 and 58\% (gastric, 0\%; duodenum, 0\%; pancreas, 29\%; small intestine, 58\%; appendix, 33\%; and colorectal, 33\%; Fig. 1B). A direct comparison of pancreatic and small intestinal NETs identified that PCR test values were almost identical (95 vs $100 \%, P=\mathrm{NS})$, but the CgA test was more often negative in the pancreas group ( 29.2 vs $\left.58 \%, \chi^{2}=5.5, P=0.014\right)$. Overall, the PCR values were elevated in 73 (97\%) of NETs when CgA was in the normal range. This is of particular relevance in PNETs, where 27 (93.1\%) of the 29 individuals with normal CgA exhibited an elevated multigene test.

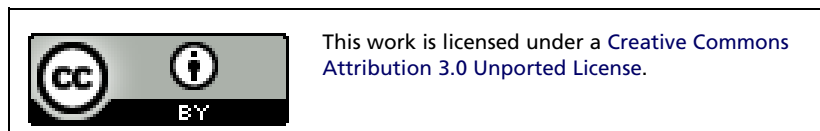



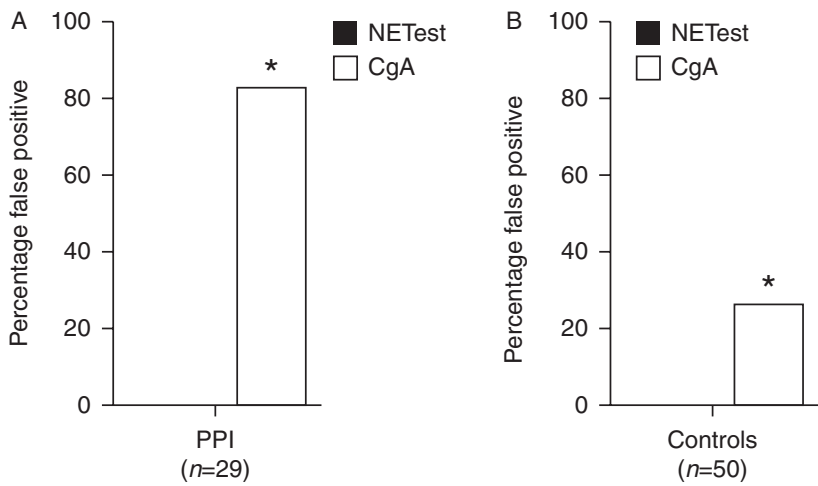

Figure 2

Evaluation of false-positives for PCR analysis compared with $\mathrm{CgA}$ (Group 2). (A) In the PPI group, the multigene test was $100 \%$ negative. However, $\mathrm{CgA}$ was elevated in $>80 \%$ of PPI-treated individuals. This was statistically significant $\left({ }^{*} \chi^{2}=37.6, P<10^{-10}\right.$ ). (B) In the control group, none $(0 \%)$ had an elevated PCR score. However, CgA levels were elevated in $13(26 \%)\left({ }^{*} \chi^{2}=12.7, P<10^{-3}\right) . C g A$, chromogranin $\mathrm{A}$; PPI, proton pump inhibitor.

Relationship with grade, stage, and treatment - The PCR score was positive in 123 (98\%) of the samples irrespective of the grade (G1-G3) or stage (local or disseminated), whether the patient was treatment-naïve $(27 / 27,100 \%$ positive) or was on concomitant somatostatin analog (SSA) therapy (32/32). The two patients who did not have a positive score were both pancreatic: one was a $13 \mathrm{~mm}$ pancreatic NET, which had cystic features, and the second was neuroendocrine and subsequently identified to be a pancreatic metastasis from an ovarian NET. In both cases, CgA was normal. Eleven patients (9\%) were on concomitant PPI therapy to control disease symptoms (ZES). All had positive PCR scores as well as CgAs. Elevated CgA levels exhibited no concordance with either grade or stage of disease or with SSA use.

\section{Group 2}

Prospectively collected proton pump inhibitortreated patients $(\boldsymbol{n}=29)$ - None $(0 \%)$ had a positive PCR score $\geq 2$ (positive test). In contrast, 24 (82.6\%) exhibited an elevated (positive) CgA (ranging from 23 to $370 \mathrm{U} / \mathrm{l}$, Fig. 2A). The false-positive CgA result was highly significant $\left(\chi^{2}=37.6, P<10^{-10}\right)$.

Controls $(\boldsymbol{n}=\mathbf{5 0}) \vee$ None $(0 \%)$ had a PCR score $\geq 2$ (positive test). In contrast, 13 (26\%) exhibited an elevated CgA (ranging from 3.1 to $93.7 \mathrm{U} / \mathrm{l}$, Fig. 2B). The falsepositive result for $\mathrm{CgA}$ was highly significant $\left(\chi^{2}=12.7\right.$, $P<10^{-3}$ ).

http://www.endocrineconnections.org DOI: 10.1530/EC-14-0100

\section{Performance metrics}

Overall, we examined the multigene test in 204 patients and controls, 61\% (125) of whom can be considered as true positives (e.g. NETs). The remainder included GERD patients $(n=29)$, none of whom had NETs (previous or current history) and 50 controls, $\sim 50 \%$ of whom were $>50$ years of age (none with past or current history of NETs). Overall, Group 1 was older (mean age 56.7 years (25-82)) than Group 2 (mean age 50.5 years (28-79), $P=0.02$ ), but no significant differences were noted between genders (33.6\% (Group 1) and 43\% (Group 2) men respectively). The performance metrics for differentiating a NET using the multigene test in these 204 patients and controls were: sensitivity 98.4\% (95\% CI:
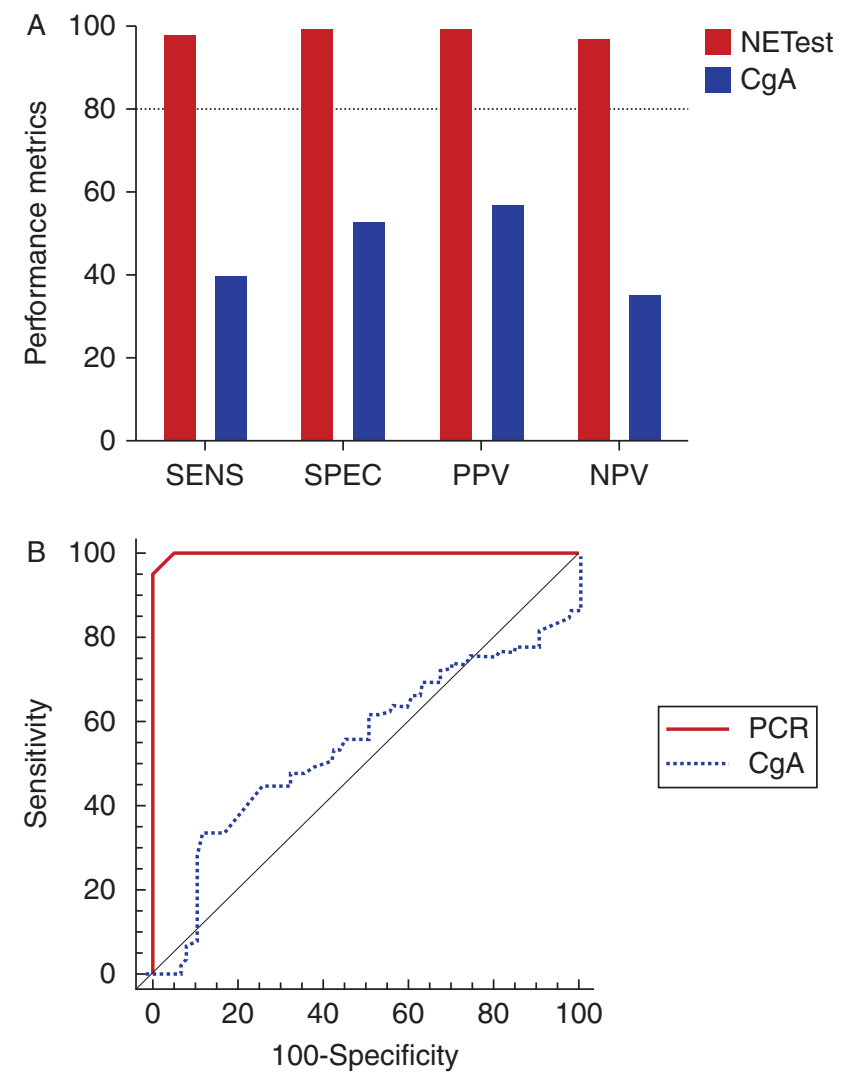

Figure 3

Performance metrics for the multigene test vs CgA. (A) The sensitivity, specificity, PPV, and NPV for the multigene test were all $>80 \%$. The metrics for $\mathrm{CgA}$ ranged from 39 to $57 \%$. (B) Receiver operating characteristic (ROC) curves for PCR gene analysis compared with CgA. The AUC for PCR gene analysis was 0.997 and for $\mathrm{CgA} 0.54$. This difference was highly significant (Z-statistic: 10.44, $P<0.0001$ ). The analyzed group included 125 NETs (all subtypes) and 79 controls (PPI treated, $n=29$ and controls, $n=50$ ). PCR, multigene test; CgA, chromogranin A; SENS, sensitivity; SPEC, specificity; PPV, positive predictive value; NPV, negative predictive value. The dotted line $(A)$ represents $80 \%$ (standard cut-off level for biomarkers).

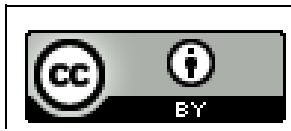

This work is licensed under a Creative Commons Attribution 3.0 Unported License. 
94.3-99.8\%), specificity 100\% (95.9-100\%), positive predictive value (PPV) 100\% (97.0-100\%), and negative predictive value (NPV) 97.8\% (92.3-99.7\%) (Fig. 3A). The AUC from the ROC curve for the multigene test was 0.997 (95\% CI: 0.974-1.0, $P<0.0001$; Fig. 3B). For the CgA assay, these were as follows: sensitivity $40 \%$ (95\% CI: $31.4-49.1 \%$ ), specificity 53.2\% (41.6-64.5\%), PPV 57.5\% (46.4-68\%), and NPV 35.9\% (27.2-45.3\%). The AUC was 0.54 (95\% CI: $0.47-0.62, P=0.32)$. A direct comparison of the AUCs (Hanley \& McNeil (34)) identified that these were significantly different (difference between areas: 0.454, 95\% CI: 0.37-0.54, Z-statistic $=10.44, P<0.0001)$.

\section{Discussion}

In NET disease, the identification of minimally detectable tumor activity or surrogates of tumor behavior is a key goal for early detection of alterations in tumor growth and metastasis, as well as for the assessment of therapeutic efficacy. To date, the use of either single-specific tumor products (e.g. serotonin, PP, and neuron specific enolase (NSE)) or a general marker of neuroendocrine secretion (CgA) has not met the rigorous criteria to be considered optimally effective in attaining these goals. We therefore utilized a PCRbased tool for the identification of GEP-NETs in peripheral blood to assess the diagnosis of NETs and evaluate the effect of common clinical situations, including PPI administration on test scores. In addition, we compared these results with CgA plasma measurements to assess comparability.

The PCR-based methodologies are widely considered as useful when the starting materials (e.g. circulating tumor cells or mRNA) are limited and require highly sensitive (35) and accurate tests (36). In the current study, we demonstrate that the PCR measurement of 51 multigene transcripts is highly accurate (98.4\%) in the detection of NETs, and that it can detect a range of tumor types including GEPderived tumors, and lesions with unknown primaries as well as bronchial and ovarian NETs. In particular, all grades were equally and effectively captured by the PCR test including $12 \mathrm{G} 3$ tumors (gastric, pancreas, lung, and biliary tract) and no differences in a positive result were noted for local (including small benign insulinomas $\sim 12 \mathrm{~mm}$ diameter) or metastatic tumors (including liver and bone deposits). In particular, the use of SSAs was not associated with a negative test; all SSA-treated patients exhibited a positive PCR score. In addition, PCR analysis was positive in 97\% of tumors when CgA levels are normal. This may be particularly useful in pancreatic NETs $(<20 \%$ had elevated $\mathrm{CgA}$ levels in the current study). Two tumors not identified by the PCR test were both pancreatic: one a $13 \mathrm{~mm}$ lesion, identified on pathology to have cystic features and the second, a lesion subsequently identified to be an ovarian metastasis.

Overall, using a number of different analytic methods of performance (performance metrics, ROC curve analysis), the multigene test significantly outperformed CgA in the detection of NETs. The sensitivities and specificities in this independent data set $(98-100 \%)$ are similar to those previously reported (85-98\% sensitivity and 93-97\% specificity) undertaken in different sample sets (22). The AUC (from the ROC curve) in the current study was 0.997, similar to that previously reported (95-98\%) (22). CgA, in contrast, exhibited performance metrics $<60 \%$ and the AUC from the ROC curve was 0.54. ROC curves for CgA generally range from 0.48 to $0.76(12,37,38)$. These poor metrics have in recent times led a number of investigators to question its utility in NETs $(12,38)$.

While several commercially available and laboratorydeveloped assays have been developed (based on targeting different secretory fragments) (11), the calculated CgA level varies broadly between test platforms, all of which have varying sensitivities and specificities (39), and widely differing coefficients of variations (40). This reflects the highly heterogeneous antigen composite released by NETs following exocytosis, which comprise both the complete protein as well as a series of cleavage products that are smaller biologically active peptides (vasostatin I and II, chromacin, pancreastatin, WE14, parastatin, and catestatin) $(8,10)$. This is complicated by the fact that $\mathrm{CgA}$ processing varies between different neuroendocrine tissues, such that there is more extensive cleavage of $\mathrm{CgA}$ in pancreatic islets than in the adrenals, and different fragment profiles exist for each of the pancreatic alpha, beta, D, and PP cells (41). This has led to the development of different antibodies in the individual $\mathrm{CgA}$ immunoassays, which exhibit varying levels of detection $(39,42)$. A comparison of three commercial kits identified a range in sensitivities (67-93\%) and specificities (85-95\%) for the detection of NETs (39). In a second study of eleven assays, only four measured concentrations correlated with total CgA (42). Overall, the assays tend to be poorly correlated $<30 \%$ (10). Irrespective of the kit type, no universally accepted CgA assay currently exists. Attempts at using more than one assay (43), or reconfiguring the CgA score to include other markers (44), only marginally increases the performance metrics and adds complex confounding variables (cost, inter-assay variation, and questions of interpretation). In a recent comprehensive analysis of this issue by Lewis \& Yao (26), the authors have concluded that CgA could be supplemented or supplanted by PCR-based 
analysis of NET genes detectable in the blood transcriptome.

An effective circulating biomarker must exhibit three key technical attributes (45): i) the marker must be present in peripheral body fluid; ii) it must be easy to detect or quantify in assays that are both affordable and robust; and iii) its appearance must be associated as specifically as possible with a particular tumor, preferably in a quantifiable manner. In addition, the measurement of a biomarker should be accurate, reliable, and differentiate between normal and specific diseases. The performance metrics, including the AUC, should be $>80 \%$ (46). The NET PCR transcript analysis meets these criteria. Conversely, using these criteria, $\mathrm{CgA}$ can be considered neither reliable nor robust, particularly given its confounding associations with a wide variety of non-NET conditions and commonly used medications. Unfortunately, clinicians are, to a large extent, unaware of such limitations and that $\mathrm{CgA}$ is only a moderately effective GEP-NET tumor biomarker.

The PPIs, in particular, represent a major iatrogenic cause of elevated circulating CgA levels. They are prescribed for GERD, esophagitis, acid hypersecretory states, peptic ulcers, and eradication of Helicobacter pylori. Overall, they are amongst the highest selling drugs worldwide $(47,48)$. Omeprazole therapy may result in CgA elevations that are in excess of $690 \mu \mathrm{g} / \mathrm{l}$ (mean $45 \pm$ $18 \mu \mathrm{g} / \mathrm{l}$ (normal range: 16-97 $\mu \mathrm{g} / \mathrm{l}$ : CIS Kit (Bedford, MA, USA))) and can occur as early as 6 days after the first intake of the agent (16). CgA concentration is higher with PPI usage compared with the alternative class of acid suppressive agents, the histamine type 2 receptor antagonists $\left(\mathrm{H}_{2} \mathrm{RA}\right)$, given the more potent gastrin elevating capacity of the former group (49). As predicted, higher CgA levels are noted after long-term treatment (1-8 years) compared with mid-term ( $<1$ year) or short (weekly/ intermittent) treatment, reflecting the effect of sustained gastrin levels in increasing the proliferation of fundic ECL cells and may also cause G-cell hyperplasia $(50,51)$. In these circumstances, apart from elevated $\mathrm{CgA}$, precursor neuroendocrine lesions of the fundus have been considered as a potential hazardous consequence of acid suppression (52). The widespread use of PPIs with consequent false positives $(80 \%$ in the current study, but in up to $100 \%$ (39)) in measurement of this protein (and its fragments) amplifies the general clinical problem of diagnosis and management if decisions are based upon CgA as a NET biomarker. Thus, increases in CgA in such patients are usually consequent upon gastric and duodenal neuroendocrine cell hyperplasia $(50,51)$ (which is reversible following PPI withdrawal (52)). In contrast, the normal PCR values in these patients demonstrate that the molecular signature measures a tumor-specific event.

Peripheral blood biomarkers are considered to be a major resource for the prediction of disease and in aiding early diagnosis, as well as in setting standards (baselines) for the measurement of current or new remedies in disease treatment. The PCR multigene transcript analysis, unlike $\mathrm{CgA}$, provides an accurate and sensitive measure of NET disease that is not affected by current acid inhibitory therapy. Furthermore, an additional advantage of the multianalyte marker set especially in NETs that are often indolent in their behavior (7) is that it can capture dynamic aspects of tumor biology. The cost of this MAAA test is currently unknown and undetermined since the insurance payers are the ultimate arbiter of reimbursement for molecular diagnostic tests. Economic analyses of MAAAs, however, demonstrate that development and clinical trials of biomarkers is cost-effective and provides both benefit as well as considerable cost-saving to society (approximately tenfold US\$ benefit in terms of quality of life) (53). More pertinently, cancer center groups, such as the National Comprehensive Cancer Network (NCCN), have endorsed the use of highperformance biomarkers particularly in fields where there are no better alternatives (54). Irrespective of economic considerations, the high-sensitivity and specificity parameters of the NETest are consistent with an accurate and sensitive tool to identify NETs and assess disease progress using peripheral blood samples.

\section{Declaration of interest}

The authors declare that there is no conflict of interest that could be perceived as prejudicing the impartiality of the research reported.

\section{Funding}

This work was supported by Clifton Life Sciences.

\section{References}

1 Modlin IM, Moss SF, Chung DC, Jensen RT \& Snyderwine E. Priorities for improving the management of gastroenteropancreatic neuroendocrine tumors. Journal of the National Cancer Institute $2008 \mathbf{1 0 0}$ 1282-1289. (doi:10.1093/jnci/djn275)

2 Modlin IM, Latich I, Zikusoka M, Kidd M, Eick G \& Chan AK. Gastrointestinal carcinoids: the evolution of diagnostic strategies. Journal of Clinical Gastroenterology 200640 572-582. (doi:10.1097/ 00004836-200608000-00003)

3 Turner GB, Johnston BT, McCance DR, McGinty A, Watson RG, Patterson CC \& Ardill JE. Circulating markers of prognosis and response

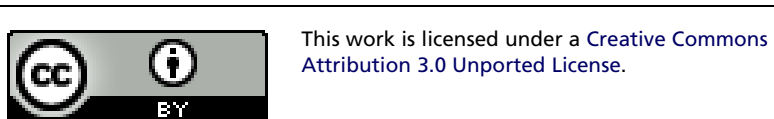


to treatment in patients with midgut carcinoid tumours. Gut 2006 55 1586-1591. (doi:10.1136/gut.2006.092320)

4 Ardill JE \& Erikkson B. The importance of the measurement of circulating markers in patients with neuroendocrine tumours of the pancreas and gut. Endocrine-Related Cancer 200310 459-462. (doi:10.1677/erc.0.0100459)

5 Meijer WG, Kema IP, Volmer M, Willemse PH \& de Vries EG. Discriminating capacity of indole markers in the diagnosis of carcinoid tumors. Clinical Chemistry 200046 1588-1596.

6 Metz DC \& Jensen RT. Gastrointestinal neuroendocrine tumors: pancreatic endocrine tumors. Gastroenterology 2008135 1469-1492. (doi:10.1053/j.gastro.2008.05.047)

7 Modlin IM, Oberg K, Chung DC, Jensen RT, de Herder WW, Thakker RV, Caplin M, Delle Fave G, Kaltsas GA, Krenning EP et al. The current status of gastroenteropancreatic neuroendocrine tumors. Lancet Oncology 20089 61-72. (doi:10.1016/S1470-2045(07)70410-2)

8 Kanakis G \& Kaltsas G. Biochemical markers for gastroenteropancreatic neuroendocrine tumours (GEP-NETs). Best Practice \& Research. Clinical Gastroenterology 201226 791-802. (doi:10.1016/j.bpg.2012.12.006)

9 Stridsberg M, Oberg K, Li Q, Stridsberg M, Eriksson B, Lundquist G \& Skogseid B. Measurement of chromogranin A, chromogranin B (secretogranin I), chromogranin C (secretogranin II) and pancreastatin in plasma and urine from patients with carcinoid tumours and endocrine pancreatic tumours. Journal of Endocrinology 1995144 49-59. (doi:10.1677/joe.0.1440049)

10 Lawrence B, Gustafsson BI, Kidd M, Pavel M, Svejda B \& Modlin IM. The clinical relevance of chromogranin A as a biomarker for gastroenteropancreatic neuroendocrine tumors. Endocrinology and Metabolism Clinics of North America 201140 111-134. (doi:10.1016/ j.ecl.2010.12.001)

11 Modlin IM, Gustafsson BI, Moss SF, Pavel M, Tsolakis AV \& Kidd M. Chromogranin A - biological function and clinical utility in neuro endocrine tumor disease. Annals of Surgical Oncology 201017 2427-2443. (doi:10.1245/s10434-010-1006-3)

12 Marotta V, Nuzzo V, Ferrara T, Zuccoli A, Masone M, Nocerino L, Del Prete M, Marciello F, Ramundo V, Lombardi G et al. Limitations of chromogranin A in clinical practice. Biomarkers 201217 186-191. (doi:10.3109/1354750X.2012.654511)

13 Wu JT, Erickson AJ, Tsao KC, Wu TL \& Sun CF. Elevated serum chromogranin $\mathrm{A}$ is detectable in patients with carcinomas at advanced disease stages. Annals of Clinical and Laboratory Science 200030 175-178.

14 Sciarra A, Monti S, Gentile V, Salciccia S, Gomez AM, Pannunzi LP \& Di Silverio F. Chromogranin A expression in familial versus sporadic prostate cancer. Urology 200566 1010-1014. (doi:10.1016/j.urology. 2005.05.045)

15 Hsiao RJ, Mezger MS \& O'Connor DT. Chromogranin A in uremia: progressive retention of immunoreactive fragments. Kidney International 199037 955-964. (doi:10.1038/ki.1990.71)

16 Giusti M, Sidoti M, Augeri C, Rabitti C \& Minuto F. Effect of short-term treatment with low dosages of the proton-pump inhibitor omeprazole on serum chromogranin A levels in man. European Journal of Endocrinology 2004150 299-303. (doi:10.1530/eje.0.1500299)

17 Waldum HL, Arnestad JS, Brenna E, Eide I, Syversen U \& Sandvik AK. Marked increase in gastric acid secretory capacity after omeprazole treatment. Gut 199639 649-653. (doi:10.1136/gut.39.5.649)

18 de Souto Barreto P, Lapeyre-Mestre M, Mathieu C, Piau C, Bouget C, Cayla F, Vellas B \& Rolland Y. Prevalence and associations of the use of proton-pump inhibitors in nursing homes: a cross-sectional study. Journal of the American Medical Directors Association 201314 265-269. (doi:10.1016/j.jamda.2012.10.018)

19 Gerson LB, Kahrilas PJ \& Fass R. Insights into gastroesophageal reflux disease-associated dyspeptic symptoms. Clinical Gastroenterology and Hepatology 20119 824-833. (doi:10.1016/j.cgh.2011.05.015)

20 Curtis KA, Hanson DL, Kennedy MS \& Owen SM. Evaluation of a multiplex assay for estimation of HIV-1 incidence. PLOS ONE 20138 e64201. (doi:10.1371/journal.pone.0064201)
21 Hood L \& Tian Q. Systems approaches to biology and disease enable translational systems medicine. Genomics, Proteomics \& Bioinformatics 201210 181-185. (doi:10.1016/j.gpb.2012.08.004)

22 Modlin I, Drozdov I \& Kidd M. The identification of gut neuroendocrine tumor disease by multiple synchronous transcript analysis in blood. PLOS ONE 20138 e63364. (doi:10.1371/journal.pone.0063364)

23 Modlin I, Drozdov I \& Kidd M. Gut neuroendocrine tumor blood qPCR fingerprint assay: characteristics and reproducibility. Clinical Chemistry 201452 419-429. (doi:10.1515/cclm-2013-0496)

24 Modlin I, Drozdov I, Alaimo D, Callahan S, Teixeira N, Bodei L \& Kidd M. A multianalyte PCR blood test outperforms single analyte ELISAs for neuroendocrine tumor detection. Endocrine-Related Cancer 201421 615-628. (doi:10.1530/ERC-14-0190)

25 Modlin I, Drozdov I \& Kidd M. A multitranscript blood neuroendocrine tumor molecular signature to identify treatment efficacy and disease progress. Journal of Clinical Oncology 201331 (Suppl) A4137.

26 Lewis MA \& Yao JC. Molecular pathology and genetics of gastrointestinal neuroendocrine tumours. Current Opinion in Endocrinology, Diabetes, and Obesity 201344

27 Faltin B, Zengerle R \& von Stetten F. Current methods for fluorescencebased universal sequence-dependent detection of nucleic acids in homogenous assays and clinical applications. Clinical Chemistry 2013 59 1567-1582. (doi:10.1373/clinchem.2013.205211)

28 Eastman PS, Manning WC, Qureshi F, Haney D, Cavet G, Alexander C \& Hesterberg LK. Characterization of a multiplex, 12-biomarker test for rheumatoid arthritis. Journal of Pharmaceutical and Biomedical Analysis 201270 415-424. (doi:10.1016/j.jpba.2012.06.003)

29 Cornejo KM, Kandil D, Khan A \& Cosar EF. Theranostic and molecular classification of breast cancer. Archives of Pathology \& Laboratory Medicine 2014138 44-56. (doi:10.5858/arpa.2012-0442-RA)

30 Lee JW \& Hall M. Method validation of protein biomarkers in support of drug development or clinical diagnosis/prognosis. Journal of Chromatography. B, Analytical Technologies in the Biomedical and Life Sciences 2009877 1259-1271. (doi:10.1016/j.jchromb.2008.11.022)

31 Raza A, Ali Z, Irfan J, Murtaza S \& Shakeel S. Analytical variables influencing the HCV RNA determination by TaqMan real-time PCR in routine clinical laboratory practice. Molecular Biology Reports 201239 7421-7427. (doi:10.1007/s11033-012-1574-3)

32 Modlin IM, Gustafsson BI, Drozdov I, Nadler B, Pfragner R \& Kidd M. Principal component analysis, hierarchical clustering, and decision tree assessment of plasma mRNA and hormone levels as an early detection strategy for small intestinal neuroendocrine (carcinoid) tumors. Annals of Surgical Oncology 200916 487-498. (doi:10.1245/s10434-008-0251-1)

33 Fleige S, Walf V, Huch S, Prgomet C, Sehm J \& Pfaffl MW. Comparison of relative mRNA quantification models and the impact of RNA integrity in quantitative real-time RT-PCR. Biotechnology Letters 200628 1601-1613. (doi:10.1007/s10529-006-9127-2)

34 Hanley JA \& McNeil BJ. A method of comparing the areas under receiver operating characteristic curves derived from the same cases. Radiology 1983148 839-843. (doi:10.1148/radiology.148.3.6878708)

35 Fink L, Seeger W, Ermert L, Hanze J, Stahl U, Grimminger F, Kummer W \& Bohle RM. Real-time quantitative RT-PCR after laser-assisted cell picking. Nature Medicine 19984 1329-1333. (doi:10.1038/3327)

36 Ginzinger DG, Godfrey TE, Nigro J, Moore DH II, Suzuki S, Pallavicini MG, Gray JW \& Jensen RH. Measurement of DNA copy number at microsatellite loci using quantitative PCR analysis. Cancer Research 200060 5405-5409.

37 Tohmola N, Itkonen O, Sane T, Markkanen H, Joenvaara S, Renkonen R \& Hamalainen E. Analytical and preanalytical validation of a new mass spectrometric serum 5-hydroxyindoleacetic acid assay as neuroendocrine tumor marker. Clinica Chimica Acta 2013 428C 38-43. (doi:10.1016/j.cca.2013.1010.1025)

38 de Laat JM, Pieterman CR, Weijmans M, Hermus AR, Dekkers OM de Herder WW, van der Horst-Schrivers AN, Drent ML, Bisschop PH, Havekes B et al. Low accuracy of tumor markers for diagnosing pancreatic neuroendocrine tumors in multiple endocrine neoplasia 
type 1 patients. Journal of Clinical Endocrinology and Metabolism 201398 4143-4151. (doi:10.1210/jc.2013-1800)

39 Stridsberg M, Eriksson B, Oberg K \& Janson ET. A comparison between three commercial kits for chromogranin A measurements. Journal of Endocrinology 2003177 337-341. (doi:10.1677/joe.0.1770337)

40 Verderio P, Dittadi R, Marubini E, Pizzamiglio S, Gion M, De Apollonia L \& Paradiso A. An Italian program of external quality control for chromogranin A (CgA) assay: performance evaluation of CgA determination. Clinical Chemistry and Laboratory Medicine 200745 1244-1250. (doi:10.1515/CCLM.2007.251)

41 Portela-Gomes GM \& Stridsberg M. Selective processing of chromogranin A in the different islet cells in human pancreas. Journal of Histochemistry and Cytochemistry 200149 483-490. (doi:10.1177/ 002215540104900408)

42 Stridsberg M, Eriksson B, Oberg K \& Janson ET. A panel of 11 regionspecific radioimmunoassays for measurements of human chromogranin A. Regulatory Peptides 2004117 219-227. (doi:10.1016/j.regpep. 2003.10.023)

43 Ramachandran R, Bech P, Murphy KG, Dhillo WS, Meeran KM, Chapman RS, Caplin M, Ghatei MA, Bloom SR \& Martin NM. Improved diagnostic accuracy for neuroendocrine neoplasms using two chromogranin A assays. Clinical Endocrinology 201276 831-836. (doi:10.1111/j.1365-2265.2011.04319.x)

44 Yao JC, Pavel M, Phan AT, Kulke MH, Hoosen S, St Peter J, Cherfi A \& Oberg KE. Chromogranin A and neuron-specific enolase as prognostic markers in patients with advanced pNET treated with everolimus. Journal of Clinical Endocrinology and Metabolism 201198 3741-3749. (doi:10.1210/jc.2011-0666)

45 Anon. Biomarkers on a roll. Nature Biotechnology 201028431. (doi:10.1038/nbt0510-431)

46 Palmer C, Duan X, Hawley S, Scholler N, Thorpe JD, Sahota RA, Wong MQ, Wray A, Bergan LA, Drescher CW et al. Systematic evaluation of candidate blood markers for detecting ovarian cancer. PLoS ONE 20083 e2633. (doi:10.1371/journal.pone.0002633)

47 Abraham NS. Proton pump inhibitors: potential adverse effects. Current Opinion in Gastroenterology 201228 615-620. (doi:10.1097/MOG. 0b013e328358d5b9)

48 Ali T, Roberts DN \& Tierney WM. Long-term safety concerns with proton pump inhibitors. American Journal of Medicine 2009122 896-903. (doi:10.1016/j.amjmed.2009.04.014)

49 Sanduleanu S, Stridsberg M, Jonkers D, Hameeteman W, Biemond I, Lundqvist G, Lamers C \& Stockbrugger RW. Serum gastrin and chromogranin A during medium- and long-term acid suppressive therapy: a case-control study. Alimentary Pharmacology \& Therapeutics 199913 145-153. (doi:10.1046/j.1365-2036.1999.00466.x)

50 Fossmark R, Jianu CS, Martinsen TC, Qvigstad G, Syversen U \& Waldum HL. Serum gastrin and chromogranin A levels in patients with fundic gland polyps caused by long-term proton-pump inhibition. Scandinavian Journal of Gastroenterology 200843 20-24. (doi:10.1080/ $00365520701561959)$

51 Mosli HH, Dennis A, Kocha W, Asher LJ \& Van Uum SH. Effect of shortterm proton pump inhibitor treatment and its discontinuation on chromogranin A in healthy subjects. Journal of Clinical Endocrinology and Metabolism 201297 E1731-E1735. (doi:10.1210/jc.2012-1548)

52 Jianu CS, Fossmark R, Viset T, Qvigstad G, Sordal O, Marvik R \& Waldum HL. Gastric carcinoids after long-term use of a proton pump inhibitor. Alimentary Pharmacology \& Therapeutics 201236 644-649. (doi:10.1111/apt.12012)

53 Thariani R, Henry NL, Ramsey SD, Blough DK, Barlow B, Gralow JR \& Veenstra DL. Is a comparative clinical trial for breast cancer tumor markers to monitor disease recurrence warranted? A value of information analysis. Journal of Comparative Effectiveness Research 2013 2 325-334. (doi:10.2217/cer.13.15)

54 Reinke T. NCCN endorses PSA testing in absence of better alternatives. Managed Care 201423 39-41.

Received in final form 17 September 2014 Accepted 14 October 2014 http://www.endocrineconnections.org DOI: 10.1530/EC-14-0100
(C) 2014 The authors Published by Bioscientifica Ltd

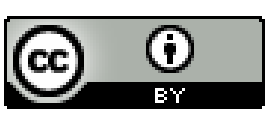

This work is licensed under a Creative Commons Attribution 3.0 Unported License. 